\title{
Preparation and Some Properties of 6-Substituted Flavins as Active Site Probes for Flavin Enzymes ${ }^{\dagger}$
}

\author{
Sandro Ghisla, ${ }^{*}$ Vincent Massey, ${ }^{\ddagger}$ and Kunio Yagi \\ Institute of Applied Biochemistry, Yagi Memorial Park, Mitake, Gifu 505-01, Japan \\ Received October 31, 1985; Revised Manuscript Received February 4, 1986
}

\begin{abstract}
Azidoflavins, 6-thiocyanatoflavins, and 6-mercaptoflavins at the lumiflavin, riboflavin, FMN, and FAD level were prepared from the corresponding 6-aminoflavins and some of their properties investigated. They are bound tightly by apoflavin enzymes which bind either riboflavin, FMN, or FAD. 6-Azidoflavins undergo facile photolysis. One major product was identified as 6-aminoflavin. A further product, which was formed also during acid decomposition of the azide, results from opening of the flavin benzene ring and is proposed to have a lumazine structure. 6-Thiocyanatoflavins are easily converted by dithiothreitol to 6-mercaptoflavins. The latter are stabilized against dimerization in the presence of reducing thiols. 6-Mercaptoflavins have a $\mathrm{p} K$ of 5.9 , which corresponds to ionization of the 6-SH function. The neutral form is yellow, while the anion is green, due to a long-wavelength band $\left(\lambda_{\max } \sim 600 \mathrm{~nm}\right)$ extending beyond $700 \mathrm{~nm}$. These properties suggest the use of these 6-substituted flavins for probing the active site of flavin enzymes. Because their reactive substituents are in close proximity to the flavin N(5)-position, these 6-substituted derivatives should also serve as useful probes of the environment around the flavin N(5), a position known to be involved in all flavin-mediated redox processes.
\end{abstract}

$\mathbf{O}_{\mathrm{u}}$ the protein at the active center of enzymes has resulted to a considerable extent from the use of flavin-derived active site probes (Ghisla et al., 1976; Walsh et al., 1978; Massey et al., 1979, 1984; Schopfer et al., 1981; Biemann et al., 1983; Kasai et al., 1983; Ghisla et al., 1984; Fitzpatrick et al., 1985; Krauth-Siegel et al., 1985). They might be differentiated into three broad classes with respect to their chemical properties: (i) flavin analogues that reflect active site properties by virtue of spectral effects induced upon binding; (ii) probes that react either with a protein functional group at the active site or with solvent-borne reactants (accessibility probes); (iii) photoaffinity labeling derivatives. Until the present, functions at positions $1,2,4$, and 8 of the flavin molecule have been candidates for specific modifications, yielding information, respectively, about the interactions with the protein or solvent of positions in all three rings of the flavin structure. One part of the flavin, which

\footnotetext{
${ }^{\dagger}$ The work was supported in part by a grant from the Deutsche Forschungsgemeinschaft (Gh2/4-4) to S.G. and by a grant from the U.S Public Health Service (GM11106) to V.M.

*Address correspondence to this author at the Faculty of Biology, Universität Konstanz, D-7750 Konstanz, FRG.

${ }^{\ddagger}$ Present address: Department of Biological Chemistry, University of Michigan, Ann Arbor, MI 48109
}

has been little explored in this context, is the portion of the benzene ring closest to the catalytically important $N(5)$ position. Exceptions have been the use of isoflavin (6methyl-8-norisoalloxazine) (Choong \& Massey, 1981; Hastings et al., 1981) and of 6-hydroxyflavin coenzyme analogues, the latter having proven useful in the study of $\mathrm{p} K$ shifts induced upon binding, by virtue of their $\mathrm{p} K \sim 7$ (Mayhew et al., 1974; Thorpe \& Massey, 1983). We thus set out to attempt to introduce two types of functional groups into this part of the molecule. The azido function should serve as a photoaffinity label (Bayley \& Knowles, 1977; Chowdhry \& Westheimer, 1979; Lwowski, 1980), as has proven feasible in the case of 8-azidoflavins (Ghisla et al., 1984; Fitzpatrick et al., 1985). A mercapto function might serve as a probe for investigating the accessibility to this region of the flavin, by using its readily monitored reactivity with alkylating agents. In addition, it could also function as a chromophore sensitive to changes in the dipole moment of the active center, since it is expected to be comparable to 6-hydroxy- and 8-hydroxyflavins (Mayhew et al., 1974; Ghisla \& Mayhew, 1976) and to 8-mercaptoflavins (Massey et al., 1979) and to have a $\mathrm{p} K$ in the physiological range. The synthesis and properties of some 6-substituted flavins have been described earlier in the context of the structural elucidation of 6-S-cysteinylriboflavin, the co- 
Scheme I: Structures of 6-Substituted Flavins at Lumiflavin, Riboflavin, FMN, and FAD Levels<smiles>[R]n1c2nc3c(N)c(C)c(C)cc3n([R])c-2nc1=O</smiles>

(1)

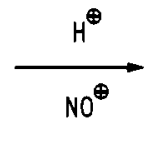

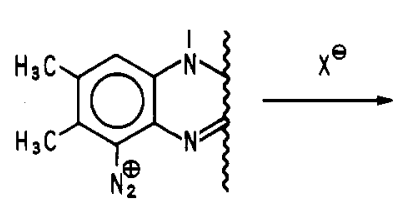

(2)<smiles>[Y]c1c(C)c(C)cc2[R]([H])c3nc(=O)n([R1])c(=O)c3nc12</smiles>

(3). (4), (5)
a: $R_{1}, R_{2}=\mathrm{CH}_{3}$ (3-Methy1-6-x-1umiflavin)
b: $R_{1}=H, R_{2}=$ D-Ribityl (6-X-riboflavin)
c: $\left.R_{1}=H, R_{2}=D-R i b i t y\right)-\left(5^{\prime}\right)-O P O_{3}^{=} \quad(6-X-F M N)$
d: $R_{1}=H, R_{2}=D-R_{i b i t y l-\left(5^{\prime}\right)-A D P \quad(6-X-F A D)}$
3: $X=-N_{3}$
4: $X=-\mathrm{SCN}$
5: $X=-S H$

factor of trimethylamine dehydrogenase (Ghisla et al., 1980). We thus attempted the synthesis of the flavin analogues mentioned above and here describe some of their properties. In work to be detailed later, it will be shown that 6-azidoflavins indeed can be excellent photoaffinity labels and that 6-thiocyanato- and 6-mercaptoflavins also are good analogues for probing the active sites of flavoproteins.

\section{ExPERIMENTAL Procedures}

Materials. The conversion of riboflavin analogues into FAD derivatives was achieved with partially purified enzymes from Brevibacterium ammoniagenes (Spencer et al., 1976). FMN analogues were obtained from the FAD precursors by hy. drolysis with Naja naja venom (Sigma Chemical Co., St. Louis, MO). The following proteins and their respective apoproteins were prepared as previously described: riboflavin-binding protein from egg white (Blankenhorn et al., 1975), flavodoxin from Megasphera elsdenii (Mayhew \& Massey, 1969; Wassink \& Mayhew, 1975), Old Yellow Enzyme from brewers bottom yeast (Abramovitz \& Massey, 1976a,b), D-amino acid oxidase from hog kidney (Yagi et al., 1967; Massey \& Curti, 1966), and lactate oxidase from $M y$ cobacterium smegmatis (Choong et al., 1975; Sullivan et al., 1977). 3-Methyl-6-nitrolumiflavin and 6-nitroriboflavin were prepared by the method of Knappe (1979). 6-Amino-3methyllumiflavin (1a) and 6-amino-riboflavin (1b) (see Scheme I) were obtained by reduction of the 6-nitro derivatives with alkaline dithionite (Ghisla et al., 1980). Riboflavin, FAD, and FMN were purchased from Sigma Chemical Co.

3-Methyllumiflavin 6-(Diazonium perchlorate) (2a). One millimole of 6-amino-3-methyllumiflavin (1a) was dissolved in the minimal amount necessary of $70 \% \mathrm{HClO}_{4}$, chilled in ice, and then diluted with 2-3 $\mathrm{g}$ of ice. A solution of saturated $\mathrm{NaNO}_{2}$ was then added dropwise until the color of the solution had turned golden orange. Solid sodium perchlorate was then added to saturate the solution, and the diazonium perchlorate was allowed to crystallize at ice temperature for approximately $20 \mathrm{~min}$ and filtered by suction. The crude orange crystals were washed with $1 \mathrm{~mL}$ of cold $1 \mathrm{M} \mathrm{HClO}_{4}$, with a little cold methanol, dried under vacuum, and then stored dry at $-20^{\circ} \mathrm{C}$. Under these conditions, the crude material $(\sim 150 \mathrm{mg})$ is stable for weeks. It was estimated to be $>90 \%$ pure, since upon reduction with hydroxylamine it yielded 6-amino-3-methyllumiflavin, which was $>90 \%$ pure as judged by high-performance liquid chromatography (HPLC). Since the riboflavin 6-diazonium salt (2b) could not be obtained as a crystalline product, it was converted in situ into its derivatives.

6-Azido-3-methyllumiflavin (3a). A total of $2.6 \mathrm{~g}(\sim 9$ $\mathrm{mmol}$ ) of 6-amino-3-methyllumiflavin (1a) was dissolved in $10 \mathrm{~mL}$ of concentrated $\mathrm{H}_{2} \mathrm{SO}_{4}$, cooled in ice, added to $100 \mathrm{~mL}$ of ice water ( $50 \mathrm{~mL}$ of water, $50 \mathrm{~g}$ of ice), and then diazotized with $900 \mathrm{mg}$ of $\mathrm{NaNO}_{2}$. A total of $500 \mathrm{mg}$ of urea was then added in order to destroy excess nitrite, followed by $5 \mathrm{~g}$ of solid sodium azide. The orange precipitate, which started forming within a few minutes, was filtered after $20 \mathrm{~min}$, washed with cold water and methanol, and dried in vacuum in the absence of light, yield $1.75 \mathrm{~g}(60 \%)$. The compound was $>95 \%$ pure by HPLC analysis. An additional $400 \mathrm{mg}$ of material of lesser purity could be crystallized from the mother liquors upon standing: MS (EI), $m / e$ (relative intensity) $311\left(\mathrm{M}^{+}, 4\right), 285$ $\left(\mathrm{M}^{+}+2-\mathrm{N}_{2}, 71\right), 28\left(\mathrm{~N}_{2}, 100\right) ;{ }^{1} \mathrm{H}$ NMR $\left(\mathrm{CF}_{3} \mathrm{COOH}\right) \delta$ (ppm) $2.56\left(\mathrm{~s}, 3 \mathrm{H}, 7-\mathrm{CH}_{3}\right), 2.79\left(\mathrm{~s}, 3 \mathrm{H}, 8-\mathrm{CH}_{3}\right), 3.74$ and $4.55\left(2 \times \mathrm{s}, 2 \times 3 \mathrm{H}, 3-\mathrm{CH}_{3}\right.$ and $\left.10-\mathrm{CH}_{3}\right), 7.85(\mathrm{~s}, 1 \mathrm{H}, 9-\mathrm{H})$; IR $(\mathrm{KBr})$, strong band at $2120 \mathrm{~cm}^{-1}\left(-\mathrm{N}_{3}\right)$, typical flavin bands (Müller et al., 1966) at $1200-1720 \mathrm{~cm}^{-1}$.

6-Azidoriboflavin (3b). One millimole $(400 \mathrm{mg}$ ) of 6aminoriboflavin (1b) was diazotized as described earlier (Ghisla et al., 1980), treated with urea to destroy excess nitrite, and then reacted with 5 equiv $(\sim 300 \mathrm{mg})$ of sodium azide. After formation of a brown solution, and upon cessation of $\mathrm{N}_{2}$ evolution, the same volume of water was added, and the compound was allowed to crystallize at ice temperature. The crude product obtained by filtration was recrystallized from acetic acid/water. The yield was $120 \mathrm{mg} \mathrm{(30 \% )} \mathrm{of} \mathrm{orange-}$ brown crystals, essentially pure as judged by HPLC and thin-layer chromatography analysis. Its UV-vis spectrum was essentially identical with that of the 6-azido-3-methyllumiflavin (3a), and the NMR spectrum was consistent with structure 3b.

Acid-Catalyzed Decomposition of 6-Azidoflavins. 6-Azido-3-methyllumiflavin (3a) (400 mg) was added in small aliquots to ice-cold, concentrated $\mathrm{H}_{2} \mathrm{SO}_{4}$ over $20 \mathrm{~min}$, care being taken to prevent heating. When the evolution of $\mathrm{N}_{2}$ had ceased, the solution was diluted with $20 \mathrm{~mL}$ of ice/water and then allowed to stand overnight at $0-4{ }^{\circ} \mathrm{C}$. A brown precipitate was then collected, which consisted of essentially pure 3,8-dimethyl-6-carboxy-7-(2-methyl-3-oxobut-2-enyl)lumazine (8a). The material can be recrystallized from glacial acetic acid/water: yield $\sim 300 \mathrm{mg}(75 \%) ;{ }^{1} \mathrm{H}$ NMR $\left(\mathrm{Me}_{2} \mathrm{SO}-d_{6}\right)$ $\delta(\mathrm{ppm}) 1.40\left[\mathrm{~s}, 3 \mathrm{H}, 7\left(3^{\prime}\right)-\mathrm{CH}_{3}\right], 2.23[\mathrm{~d}, J=3.7 \mathrm{~Hz}, 3 \mathrm{H}$, $\left.7\left(2^{\prime}\right)-\mathrm{CH}_{3}\right], 3.25$ and $3.90\left(2 \times \mathrm{s}, 2 \times 3 \mathrm{H}, 3-\mathrm{CH}_{3}\right.$ and $\left.8-\mathrm{CH}_{3}\right)$, $7.01(\mathrm{~d}, J=3.7 \mathrm{~Hz}, 1 \mathrm{H}, 9-\mathrm{H})$; MS (CI/DI, isobutane), $m / e$ (relative intensity) $319\left(\mathbf{M}^{+}+1,3\right), 303\left(\mathbf{M}^{+}-15,15\right), 287$ $\left(\mathrm{M}^{+}-31,100\right)$; IR $(\mathrm{KBr})$, strong bands at $1270,1490,1580$, 1630 , and $1700 \mathrm{~cm}^{-1}$. Anal. Calcd for $\mathrm{C}_{14} \mathrm{H}_{14} \mathrm{~N}_{4} \mathrm{O}_{5}$ : C, 52.83; $\mathrm{H}, 4.40 ; \mathrm{N}, 17.61$. Found: C, 52.93; $\mathrm{H}, 4.65 ; \mathrm{N}, 17.60$.

6-Azido-FAD (3d). One milliliter of a solution of 6amino-FAD $(1 \mathrm{c})\left(A_{430} \sim 17\right)$ was diluted at ice temperature with $1 \mathrm{~mL}$ of $1 \mathrm{~N} \mathrm{HCl}$; then, $2 \mu \mathrm{L}$ of a saturated $\mathrm{NaNO}_{2}$ solution was added, which caused the green solution to turn 
golden yellow within $10 \mathrm{~s}$. Then, $50 \mu \mathrm{L}$ of saturated urea and, after $\sim 10 \mathrm{~s}, 50 \mu \mathrm{L}$ of saturated sodium azide were added; the latter induces $\mathrm{N}_{2}$ evolution and formation of an orange-yellow solution. After $\sim 30 \mathrm{~s}$, the solution was treated with $100 \mu \mathrm{L}$ of $2 \mathrm{M}$ sodium acetate and subsequently with $200 \mu \mathrm{L}$ of saturated trisodium phosphate to bring the $\mathrm{pH}$ to $4-4.5$. The $\mathrm{pH}$ of the solution was then adjusted to 6-7 with solid bicarbonate and could be used without further manipulations for most enzyme reconstitution experiments. It could be freed of salts as described below for $\mathbf{4 d}$.

6-Thiocyanato-FAD (4d). Diazotization of 6-amino-FAD (1c) was carried out as described above, however in $0.1 \mathrm{M}$ $\mathrm{H}_{2} \mathrm{SO}_{4}$. After addition of urea and $200 \mu \mathrm{L}$ of saturated $\mathrm{NH}_{4} \mathrm{SCN}$ solution, the solution was immediately treated with the amount of $2 \mathrm{M}$ sodium acetate necessary to bring the $\mathrm{pH}$ to 4-4.5. At this point the formation of the 6-thiocyanate was followed by recording the absorption spectrum of an aliquot. The conversion was essentially complete after $20-30 \mathrm{~min}$ at this $\mathrm{pH}$ and ice temperature and is dependent on the concentration of $\mathrm{NH}_{4} \mathrm{SCN}$ and $\mathrm{pH}$. Thereafter, the $\mathrm{pH}$ of the solution was adjusted to 6-7, and the material could be used directly to reconstitute holoenzymes. The FAD derivative was freed of salt by chromatography on a column of Bio-Gel P-2 $(100 \times 2.5 \mathrm{~cm})$ equilibrated and eluted with glass-distilled water. As with most flavins (Spencer et al., 1976), the 6SCN-FAD migrates as a sharp band, well separated from a minor impurity at the FMN level.

6-Thiocyanatoriboflavin (4b). This was prepared analogously to the 6-thiocyanato-FAD; however, $1 \mathrm{~N} \mathrm{HCl}$ or $1 \mathrm{M}$ $\mathrm{H}_{2} \mathrm{SO}_{4}$ was used in the diazotization step.

6-Mercaptoflavins (5b-d). These compounds were prepared from the corresponding 6-thiocyanatoflavin by reaction at $\mathrm{pH}$ 7 with a small excess of dithiothreitol. Providing that a low concentration $(\geq 10 \mu \mathrm{M})$ of ethylenediaminetetraacetic acid (EDTA) is present to prevent trace metal catalyzed oxidation of the thiols, the 6-mercaptoflavins are stable for several hours at $25^{\circ} \mathrm{C}$. The conversion is conveniently followed spectrophotometrically at $440 \mathrm{~nm}$, where a large extinction increase is observed, or at $600 \mathrm{~nm}$, where the mercaptoflavin anion has substantial absorption (Ghisla et al., 1980).

Instrumentation. Absorption spectra were recorded with a Shimadzu MPS 2000 or a Shimadzu UV-250 spectrophotometer at $25^{\circ} \mathrm{C}$, when not otherwise indicated. NMR spectra were obtained with a JEOL FX-90 instrument using tetramethylsilane as an internal standard. Infrared spectra in $\mathrm{KBr}$ pellets were measured with a Hitachi 270-30 instrument. Mass spectra were obtained with a JEOL DX-300 instrument. HPLC analysis and preparative separations were done with a Shimadzu LC-4A instrument using a Develosil $(30 \times 0.7$ $\mathrm{cm}) \mathrm{RP}_{18}$ column and the following elution conditions: for lumiflavin and riboflavin derivatives, $90 \% \mathrm{MeOH} / 0.01 \mathrm{M}$ phosphate buffer, $\mathrm{pH} 6.0$, at volume ratios $4 / 6$ from 0 to 2 min, then a gradient to $10 / 0$ from 2 to $14 \mathrm{~min}$, and maintaining this to $20 \mathrm{~min}$; for FMN and FAD derivatives, $90 \%$ $\mathrm{MeOH} / 0.01 \mathrm{M}$ phosphate, $\mathrm{pH} 6.0,2 / 8$ from 0 to $2 \mathrm{~min}$, then a gradient to $5 / 5$ from 2 to $14 \mathrm{~min}$, and then to $9 / 1$ from 14 to $18 \mathrm{~min}$. For the lumazine derivatives the same gradient system was used but employing acetic acid, $\mathrm{pH} 2.5$, instead of phosphate buffer.

\section{RESULTS AND Discussion}

General Comments on Synthesis of 6-Substituted Flavin Coenzymes. In a preceding paper (Ghisla et al., 1980), the synthesis and diazotization of 6-aminoflavins have been described (Scheme I). The Sandmeyer reaction of the flavin diazonium cations (2) was also shown to be a suitable path

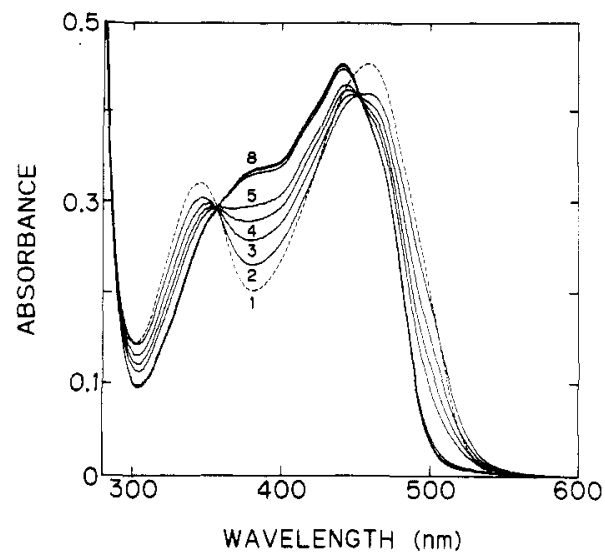

FIGURE 1: Formation of 6-thiocyanatoflavin (4) from flavin 6-diazonium cation (2). 6-Aminoriboflavin (1b) in dimethylformamide was diluted with $1 \mathrm{M}$ sulfuric acid to yield an approximately $0.5 \mathrm{M}$ solution. The diazonium cation $\mathbf{2 b}$ was then generated as described in the text and the $\mathrm{pH}$ of the solution adjusted to $\mathrm{pH} 2.5$ by addition of saturated sodium acetate solution (curve 1). To this species, 20 $\mu \mathrm{L}$ of a saturated solution of $\mathrm{NH}_{4} \mathrm{SCN}$ was added, and the spectra of curves 2-8 were recorded after $2.5,5,7.5,10,20,30$, and $60 \mathrm{~min}$, respectively. The final species consists of $90-95 \%$ 6-thiocyanatoriboflavin (4b) as judged by HPLC analysis. The formation of the FAD analogue $2 d$ proceeds analogously.

for the introduction of (pseudo)halogens into this position. However, the method involved the use of concentrated sulfuric acid and was reported to be prone to formation of side products, probably originating from decay of the diazonium salts. Strong acid was required because of the extremely low solubility of 6-aminoflavins and in particular of 6-aminoriboflavin (1b). The conditions of diazotization could be significantly improved in the present work for the preparation of 6-diazonium flavins (2) and their subsequent conversion products. Thus, 3-methyllumiflavin 6-(diazonium perchlorate) (2a) was obtained in crystalline form; this allowed the study of some of its properties and conversions. The preparation of 6-azidoflavins (3) and 6-thiocyanatoflavins (4) was miniaturized to the point where the conversion of nanomole to micromole quantities of flavins could be achieved quickly and essentially quantitatively. This was of particular importance for the synthesis of 6-substituted FAD and FMN derivatives 3c, 3d, $\mathbf{4 c}$, and $\mathbf{4 d}$. The attempted conversion of 6-azidoriboflavin (3b) and of 6-thiocyanatoriboflavin (4b) to the FMN $3 c$ and $4 c$ and FAD 3d and $\mathbf{4 d}$ derivatives with the system from $B$. ammoniagenes, which has been successful in the conversion of most riboflavin derivatives into their FAD counterparts (Spencer et al., 1976), unexpectedly failed, although conversion of 6aminoriboflavin (1b) to 6-amino-FAD (1d) succeeded with excellent yields. The reason for the failure might reside in the steric requirements of these two substituents, which, due to hindrance with the ortho functions $\left[7-\mathrm{CH}_{3}\right.$ and $\left.\mathrm{N}(5)\right]$ and their forming an angle at their proximal atom probably cannot be accomodated in the flavin plane. The preparation of the desired analogues was thus carried out via 6-amino-FAD (1d). Since under strongly acidic conditions the pyrophosphate bond of FAD will hydrolyze rapidly, a rapid and mild procedure was devised (cf. Experimental Procedures for details), which in the case of the preparation of 6-azido-FAD (3d) and 6thiocyanato-FAD (4d) yielded the desired products in $>90 \%$ purity as judged from their HPLC analysis. This is exemplified in Figure 1 for the preparation of 6-thiocyanatoflavins. That under the reaction conditions no modification of the FAD molecule occurs in the adenine moiety is evidenced by the tight binding to apoflavoenzymes such as apo-D-amino acid oxidase. This was also demonstrated directly by treating the FAD 


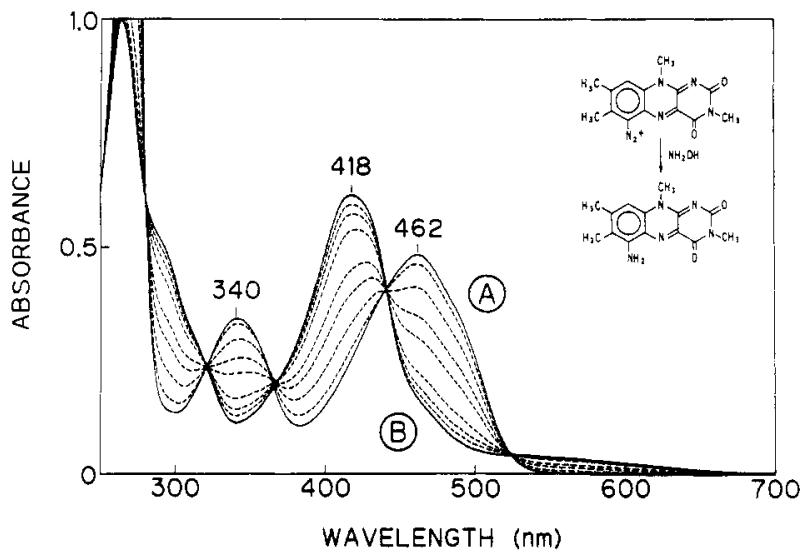

FIGURE 2: Absorption spectrum of 3-methyllumiflavin 6-diazonium cation (2a) and conversion to 6-amino-3-methyllumiflavin (1a). A total of $50 \mu \mathrm{L}$ of a stock solution of $2 \mathrm{a}$ in acetonitrile containing $1 \%$ $\mathrm{CH}_{3} \mathrm{COOH}$ was diluted into $950 \mu \mathrm{L}$ of dilute acetic acid $(\mathrm{pH} 2.5)$ (curve A). A $50-\mu \mathrm{L}$ aliquot of $1 \mathrm{M} \mathrm{NH}, \mathrm{OH} \cdot \mathrm{HCl}$ was then added, and the following curves were recorded after approximately $1,4,8$, $12,22,32$, and $42 \mathrm{~min}$. The final spectrum (curve $\mathrm{B}$ ) is identical with that of 6-amino-3-methyllumiflavin (1a) under the same conditions and was obtained after $80 \mathrm{~min}$.

derivatives $3 \mathbf{d}$ and $\mathbf{4 d}$ with Naja naja venom and HPLC analysis of the products. In both cases, as well as when ATP and $N$. naja venom were used, the product was indistinguishable from authentic adenosine (HPLC: $10 \% \mathrm{MeOH} /$ $0.01 \mathrm{M}$ phosphate buffer, $\mathrm{pH}$ 6.0). The synthetic path is outlined in Scheme I.

Some Properties and Reactions of Flavin 6-Diazonium Cations. Since the flavin 6-diazonium cations (2) are the key intermediates for the synthesis of further 6-substituted flavins and also in view of their potential use as active site probes, this class of compounds was investigated in some detail. The lumiflavin 6-(diazonium perchlorate) (2a) is stable in acetonitrile containing a trace of acid; however, in the presence of nucleophilic solvents and of base, the chromophore is destroyed irreversibly. In methanol containing traces of ammonia, or in basic or neutral aqueous solution, a chromophore with a $\lambda_{\max }$ at $365 \mathrm{~nm}$ is formed immediately, which is not stable and decays further. An indication to its possible structure is suggested by the loss of the typical strong absorption band at $\lambda 260-265 \mathrm{~nm}$, suggesting that the aromatic system of the benzene ring has been suppressed. The absorption spectrum (Figure 2) of the 6-diazonium flavin cation (2a) retains the two maxima in the visible-near-UV region of normal flavin, indicating only a minor perturbation of the chromophore; this contrasts with the spectra of other 6-substituted flavins to be detailed below. 8-Diazonium flavins were found to yield 8azidoflavins in good yield upon reaction with hydroxylamine (Fitzpatrick et al., 1985). In the present case, a completely different course of reaction was observed (Figure 2), in which 6-aminoflavin (1) was obtained essentially quantitatively. The latter was identified by its typical absorption spectrum (Ghisla et al., 1980) and by HPLC comparison with authentic material. This further confirms the structure of the flavin 6diazonium structure (2). The different reactivity of 6-substituted flavins as compared with the 8-substituted analogues was observed also in attempts to convert the 6-diazonium cation 2 to 6-hydroxyflavin by a method published earlier for 8-hydroxyflavin (Ghisla \& Mayhew., 1980), consisting of the acetolysis of $\mathbf{2}$ in glacial acetic acid followed by hydrolysis. In the present case, two main, highly fluorescent products having a flavin-like spectrum ( $\lambda_{\max }$ at 435,365 , and $\left.265 \mathrm{~nm}\right)$ were obtained, which were, however, not the expected 6-OR derivatives and were not identified further.

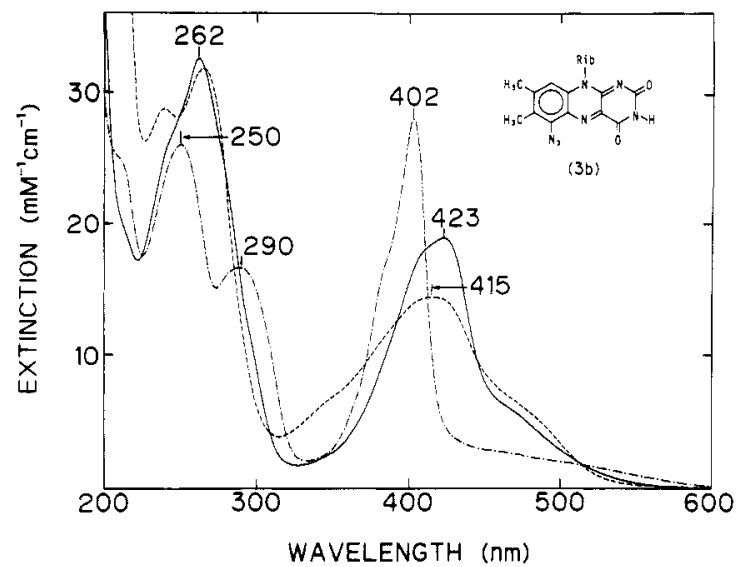

FIGURE 3: Spectra of 6-azidoriboflavin (3b) and $\mathrm{pH}$ dependence. Aliquots $(50 \mu \mathrm{L})$ of 6-azidoriboflavin in dimethylformamide were diluted with $1 \mathrm{~mL}$ each of $0.1 \mathrm{M}$ phosphate, $\mathrm{pH} 6.0(-), 50 \mathrm{mM}$ $\mathrm{NaOH}(--)$, or $20 \% \mathrm{HClO}_{4}(-\cdot-)$. Extinction coefficients were determined by titration of 6 -azidoriboflavin at $\mathrm{pH} 7.0$ with a standarized solution of riboflavin-binding protein (see text for details).

Properties and Reactions of 6-Azidoflavins. 6-Azidoriboflavin (3b) and 6-azido-3-methyllumiflavin (3a) are stable when stored as a solid in the dark. Their structure is confirmed by the ${ }^{1} \mathrm{H}$ NMR spectra, in which all the resonances of the parent compound are present (cf. Experimental Procedures), and by the IR-spectrum, which shows the characteristic strong $-\mathrm{N}_{3}$ band at $2120 \mathrm{~cm}^{-1}$. They have absorption spectra (Figure 3) lacking the typical two-banded shape of the oxidized isoalloxazine chromophore. These spectra are, on the other hand, similar to those of other 6-substituted flavins having electron-donating functions (Mayhew et a1., 1974; Schöllnhammer \& Hemmerich, 1974; Ghisla et al., 1980). The outstanding feature of 6-azidoflavins is their sensitivity to light as demonstrated in Figure 4. Thus, irradiation with the light of a desk lamp causes marked changes in the visible spectrum, concomitant with disappearance of the starting material as analyzed by HPLC (Figure 4, A, inset, and 4B). The light sensitivity is, however, at least 1 order of magnitude smaller than that of 8-azidoflavins (Ghisla et al., 1984; Fitzpatrick et al., 1985). A multitude of products appears during irradation. Although several types of reaction can be expected upon photolysis of aromatic azides (Abramovitch \& Kyba, 1971; Reiser \& Wagner, 1971), this finding is in partial contrast to what was observed with 8-azidoflavins where several photoproducts could be identified readily (Ghisla et al., 1984; Fitzpatrick et al., 1985). The ratio of the products also changes upon further irradiation, indicating secondary photoreactions. A major product was identified as 6-aminoflavin (1a) by comparison of its properties with an authentic sample. It might be formed by intermolecular reduction. The products other than 6-aminoflavin formed upon irradiation (cf. inset of Figure 4A) have a much shorter retention time on HPLC than any 6-substituted riboflavin or lumiflavin. This indicates that a major modification or breakdown of the isoalloxazine nucleus occurs. One of these products has a retention time and fluorescence characteristics (excitation maximum $410 \mathrm{~nm}$, emission maximum $480 \mathrm{~nm}$ ) matching those of the main protic solvent decay product of the lumazine derivative 8 to be described below. A major compound to be expected from photoreaction of azides (Abramovitch \& Kyba, 1971; Reiser \& Wagner, 1971) is the product of insertion of the nitrene into water, i.e., the hydroxylamine derivative. Such a compound was identified as a product from the photolysis of 8-azidoflavins (Fitzpatrick et al., 1985). The synthesis of 6-(hydroxylamino)flavin was attempted by starting from 6-chloroflavin 

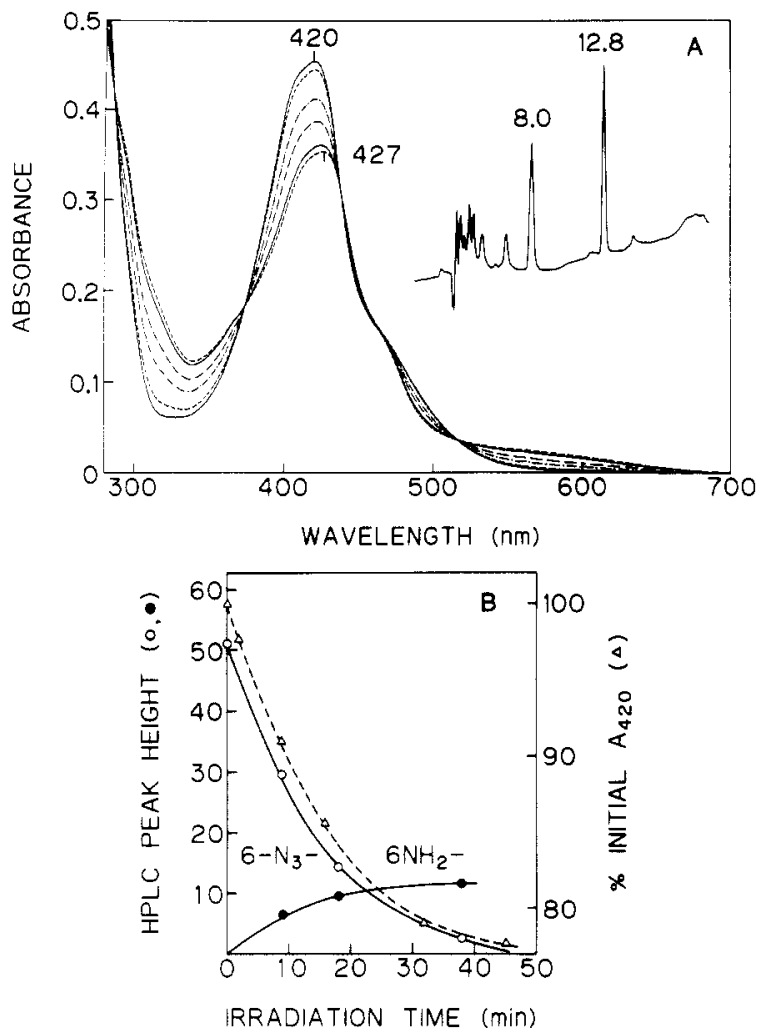

FIGURE 4: (A) Spectral course of photochemical reaction of 6-azido-3-methyllumiflavin (3a). 6-Azido-3-methyllumiflavin, $2.38 \times 10^{-4}$ $\mathrm{M}$ in $0.1 \mathrm{M}$ phosphate buffer, $\mathrm{pH} 7.0$, was irradiated with a $15-\mathrm{W}$ daylight fluorescent desk lamp (approximately $25 \mathrm{~cm}$ from the sample). (-) Starting spectrum. (-.), (-, ) , (--), (-), and (..) were obtained after $1.5,9,17,31$, and 44 min, respectively. The inset shows the HPLC analysis of a sample obtained after 18-min irradiation. The elution gradient was $0.01 \mathrm{M}$ phosphate buffer, $\mathrm{pH} 6.0 / 90 \%$ methanol as described under Experimental Procedures. 6-Azido-3methyllumiflavin (3a) elutes at $12.8 \mathrm{~min}$ and 6-amino-3-methyllumiflavin (1a) after $8.0 \mathrm{~min}$. (B) Concentration dependence of the components of the experiment of $(A)$ on the time of irradiation. $(\Delta)$ Absorbance changes at $420 \mathrm{~nm} ;(0)$ and $(\bullet)$ relative peak height of the signals corresponding to 6-azido- and 6-amino-3-methyllumiflavin, respectively, obtained from HPLC elution profiles such as that shown in the inset of (A).

(Ghisla et al., 1980). The major product obtained after incubation of this compound with excess hydroxylamine in dry dimethylformamide in the presence of $\mathrm{K}_{2} \mathrm{CO}_{3}$ was, however, 6-aminoflavin, which might have been formed from a primary 6-(hydroxylamino)flavin and its subsequent reduction by excess hydroxylamine. The elucidation of the structure of degradation product(s) is of importance in view of the projected use of 6-azidoflavins as photoaffinity labels. In view of the complexity of the mixture obtained, this promised to be a very difficult task. In order to obtain at least partial insight into the reaction pathways of photochemically generated flavin-6-nitrenes, we resorted to chemical generation and attempted the structural elucidation of at least some of the products, as detailed in the next section.

Reaction Course of Chemically Generated 3-Methyllumiflavin-6-nitrene (6). The transient nitrene 6 derived from 6-azido-3-methyllumiflavin (3a) was generated with concentrated sulfuric acid at $0{ }^{\circ} \mathrm{C}$ (Abramovitch \& Kyba, 1971). The crystalline product obtained in good yield $(75 \%)$ was homogeneous by HPLC when analyzed in a weakly acidic system ( $\mathrm{pH} 2.5$ ). It was found, however, to decay in practically every protic solvent (HPLC analysis), in particular in the presence of trace amounts of base or at high $\mathrm{pH}$. This behavior is a common feature of 8 -substituted lumazines and has been shown to involve addition of solvent to the lumazine nucleus

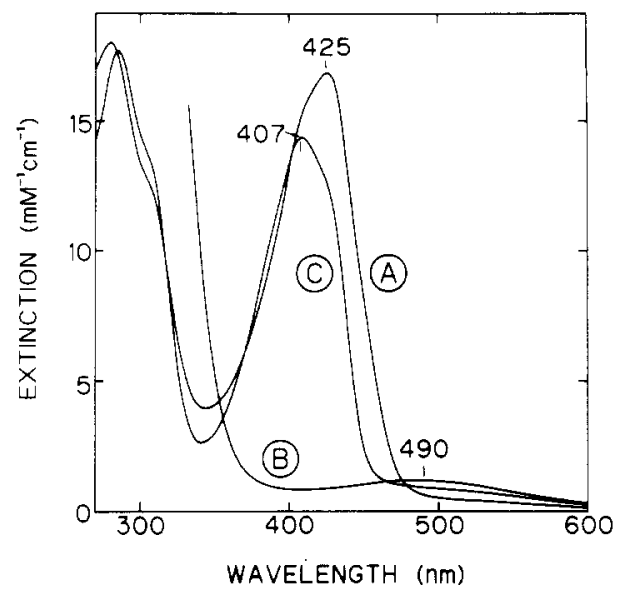

FIGURE 5: Spectral properties and redox reaction of 3,8-dimethyl6-carboxy-7-(2-methyl-3-oxobut-2-enyl)lumazine (8a). The product from acid degradation of 6-azido-3-methyllumiflavin (3a) was dissolved in dimethyl sulfoxide containing $0.3 \%$ acetic acid and then diluted 20 -fold in $0.1 \mathrm{M}$ acetate buffer, pH 5.0 (curve A). To this a grain of solid dithionite was added, and spectrum B was recorded after careful mixing. Admission of air generated the spectrum of curve C. Repetition of the dithionite/air cycles generates the species of curves $B$ and $C$

(Pfleiderer et al., 1971; Ram et al., 1982). Its spectrum (Figure 5) clearly indicates that the isoalloxazine chromophore has been drastically modified; the absence of the typical strong UV absorption, which is present in all flavins having an intact xylene subnucleus (Visser \& Müller, 1979), suggests that the latter has been modified. The IR spectrum reveals new bands attributable to carbonyl vibrations, which are not present in the parent compound. The ${ }^{1} \mathrm{H}$ NMR spectrum shows the presence of the same number of hydrogens as in the 6-azidoflavin (3a) and no additional couplings; the chemical shifts indicate a difference in environment of the methyl groups previously at $C(7)$ and $C(8)$ in 3a. The elemental analysis agrees very well with the formula $\mathrm{C}_{14} \mathrm{H}_{14} \mathrm{~N}_{4} \mathrm{O}_{5}$, consistent with either of the two structures $\mathbf{8 a}$ or $\mathbf{8 b}$ (Scheme II). This interpretation is substantiated by several lines of evidence. As required, the compound forms a crystalline derivative with $\mathrm{NH}_{2} \mathrm{OH}$, the spectrum of which is only marginally different from that of the parent compound $\left(\lambda_{\max }\right.$ at 430,285 , and 263 $\mathrm{nm}$, in methanol, not shown). The elemental analysis of this hydroxylamine derivative is consistent with the formula $\mathrm{C}_{14^{-}}$$\mathrm{H}_{15} \mathrm{~N}_{5} \mathrm{O}_{5}$, which would be derived from addition at the oxo function of $\mathbf{8 a}$. This argues against structure $\mathbf{8 b}$ in which the carbonyl function would be part of an amide and in which formation of such a derivative would not be facile and could be expected to have a major effect on the chromophore. The absorption spectrum of the compound is comparable in its $\lambda_{\max }$ and extinction coefficients (Figure 5) to those of 8-substituted lumazines. These have $\lambda_{\max }$ around $400 \mathrm{~nm}$ and similar extinction coefficients (Pfleiderer et al., 1966) and should be different from those of 8-substituted 6-oxolumazines (Pfleiderer, 1957). As required for a lumazine system, the molecule undergoes reduction by dithionite, presumably to the reduced form 9 (Figure 5). 5,8-Dihydrolumazines are reoxidized readily by oxygen, as observed (Mengel et al., 1977; Harzer $\&$ Ghisla, 1979). Of significance also is the long-wavelength band of the reduced species. Such a band is not present in normal reduced 8-substituted 7,8-dihydrolumazines (Pfleiderer \& Mengel, 1971; Lund, 1975; Harzer \& Ghisla, 1979) nor in reduced 6-oxolumazines (Pfleiderer, 1957); it was, however, observed in reduced lumazines carrying a $-\mathrm{C}=\mathrm{O}$ function at position 6 , the band being ascribed to exocyclic conjugation (Mengel et al., 1977). The long-wavelength band thus is 
Scheme II: Proposed Reaction Course of Flavin-6-nitrene Generated in Sulfuric Acid and Structures of Intermediates and Products

$$
\text { 等 }
$$

(3)
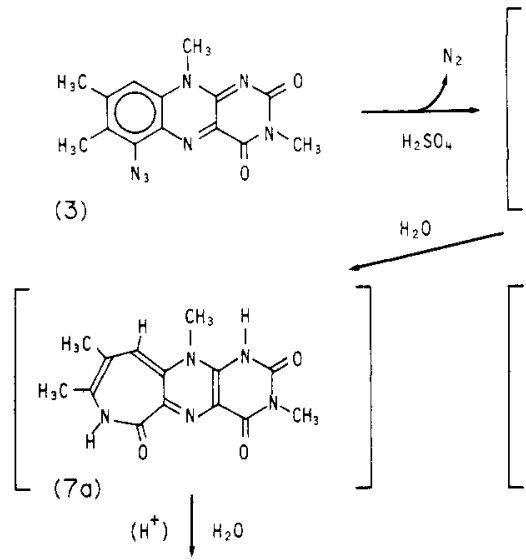

$$
\text { (6) }
$$
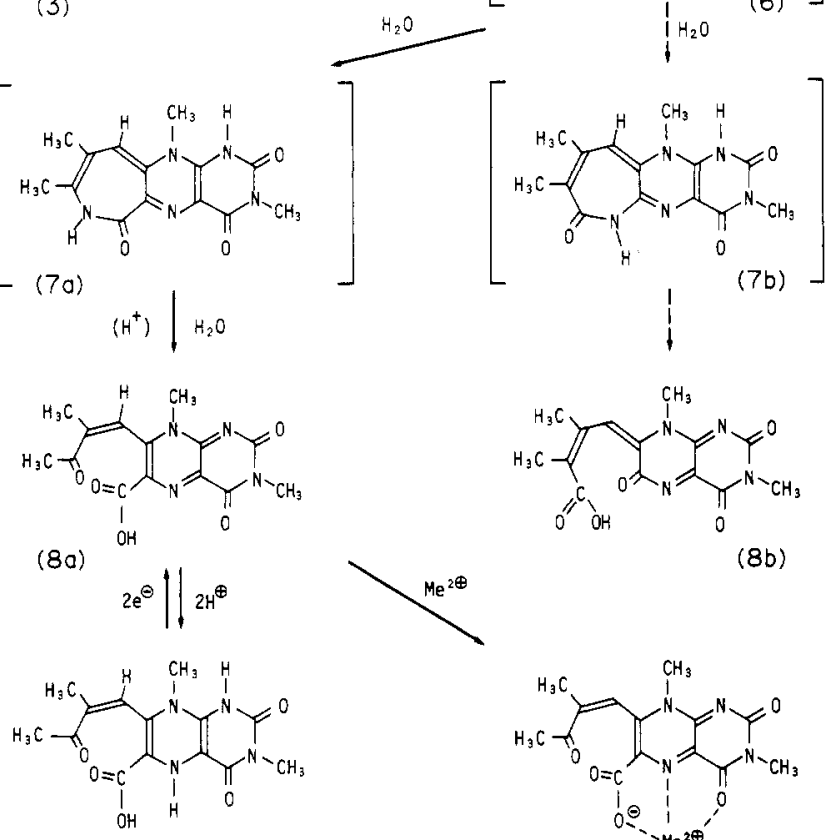

(8b)

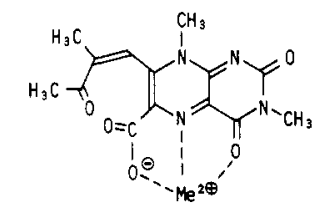

(10)

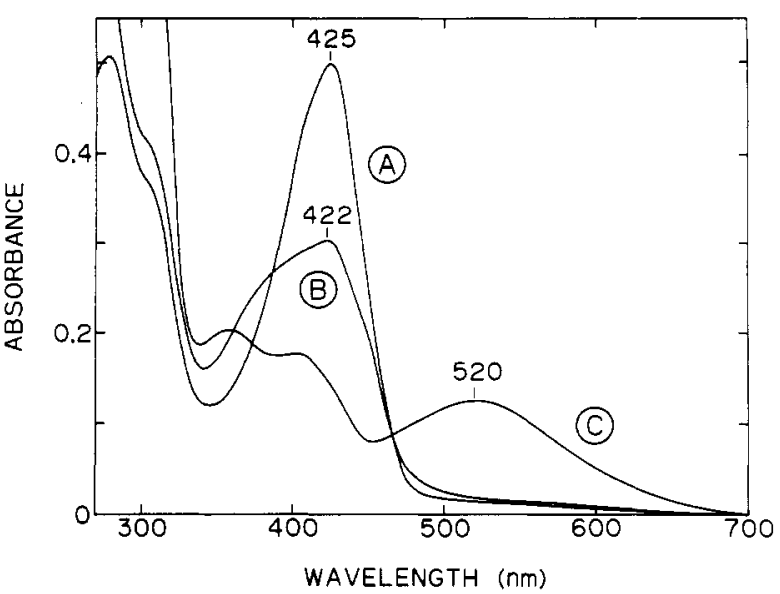

FIGURE 6: Spectral course of $\mathrm{Cu}^{2+}$ complexation of 3,8-dimethyl-6carboxy-7-(2-methyl-3-oxobut-2-enyl)lumazine (8a). The compound, $100 \mu \mathrm{L}$ of a stock solution in dimethyl sulfoxide containing $0.3 \%$ acetic acid, was diluted into $1.0 \mathrm{~mL}$ of $0.1 \mathrm{M}$ acetate buffer, $\mathrm{pH} 5.0$ (curve A). A total of $20 \mu \mathrm{L}$ of a $0.5 \mathrm{M}$ solution of $\mathrm{Cu}\left(\mathrm{NO}_{3}\right)_{2}$ in the same buffer was then added to generate the spectrum of curve B. Addition of a small amount of solid dithionite led to formation of the spectrum of curve $C$. Upon being mixed with air, a spectrum identical with that of curve $C$ of Figure 5 was obtained.

conditions. This is the probable reason for which it could not be isolated as such but only in the form of its hydrolysis product 8a. It is likely, however, that cyclic amides such as $7 \mathbf{a}$ and $\mathbf{7 b}$ are among the products observed upon photolysis (cf. Figure 4A).

Binding of 6-Azidoflavins to Apoproteins. 6-Azidoriboflavin binds tightly to the apoprotein of hen egg white riboflavinbinding protein, with a $K_{\mathrm{d}}$ value $<10^{-8} \mathrm{M}$ at $\mathrm{pH} 7.0,20^{\circ} \mathrm{C}$ (results not shown). By standardization of the apoprotein with pure riboflavin, it is thus possible to determine the extinction coefficient of both the free and bound 6-azidoriboflavin. The free flavin has a $\lambda_{\max }$ at $420 \mathrm{~nm}\left(\epsilon=19000 \mathrm{M}^{-1} \mathrm{~cm}^{-1}\right)$. On binding to the riboflavin-binding protein, the $\lambda_{\max }$ shifts to 432 $\mathrm{nm}\left(\epsilon=15100 \mathrm{M}^{-1} \mathrm{~cm}^{-1}\right) .6-\mathrm{N}_{3}$-FMN was prepared from $6-\mathrm{N}_{3}-\mathrm{FAD}$ by addition of a trace of $N$. naja venom. If one assumes that $6-\mathrm{N}_{3}$-FMN has approximately the same spectrum as 6-azidoriboflavin (an assumption based on observations with many different substituted flavins), the extinction coefficient of $6-\mathrm{N}_{3}-\mathrm{FAD}$ at its $\lambda_{\max }, 428 \mathrm{~nm}$, can be estimated as $17500 \mathrm{M}^{-1} \mathrm{~cm}^{-1}$. Thus, as with normal flavin, the FAD level has a slightly longer wavelength maximum and an approximately $10 \%$ lower extinction than the FMN-level flavin. 6-Azido-FMN has been found to bind tightly to apoflavodoxin and to the apoprotein of Old Yellow Enzyme. Bound to apoflavodoxin, the $\lambda_{\max }$ is $428 \mathrm{~nm}, \epsilon=16800 \mathrm{M}^{-1} \mathrm{~cm}^{-1}$, while the Old Yellow Enzyme form has $\lambda_{\max }=423 \mathrm{~nm}, \epsilon=15700$ $\mathrm{M}^{-1} \mathrm{~cm}^{-1}$. Bound to the apoenzyme of lactate oxidase, the $6-\mathrm{N}_{3}-\mathrm{FMN}$ has a $\lambda_{\max }$ at $428 \mathrm{~nm}$; in this case, the extinction coefficient could not be determined because of instability of the apoprotein. 6-Azido-FAD also binds to the apoprotein of D-amino acid oxidase, the $\lambda_{\max }$ shifting from 428 to $422 \mathrm{~nm}$, with essentially no change in extinction coefficient. Benzoate also binds strongly to the artificial enzyme, as it does with native enzyme (Yagi \& Ozawa, 1962; Quay \& Massey, 1977), to give a resolved spectrum with a double maximum, 432 and $488 \mathrm{~nm}, \epsilon=\sim 16000 \mathrm{M}^{-1} \mathrm{~cm}^{-1}$.

The properties of these artificial flavoproteins, including their reactions with substrates and other ligands, and the effect of light irradiation will be detailed in a separate paper ( $V$. Massey, S. Ghisla, and K. Yagi, unpublished results).

Properties of 6-Thiocyanatoflavins and 6-Mercaptoflavins. Previous studies had shown the conversion of 6-thiocyanato- 


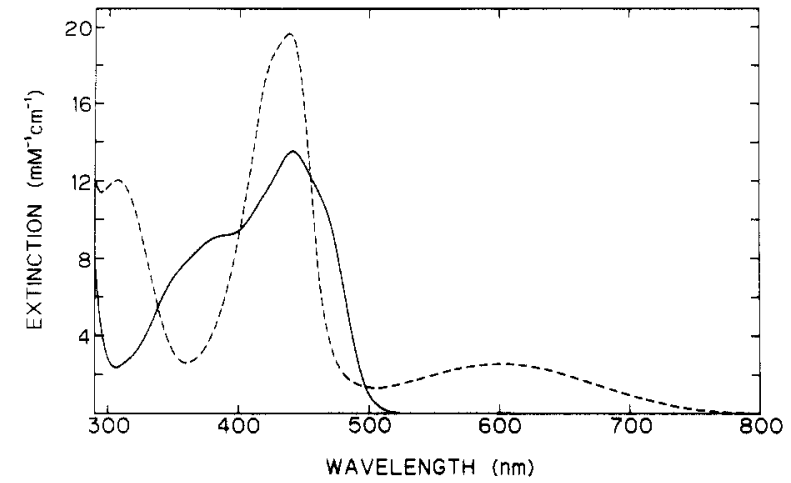

FIGURE 7: Absorption spectra of 6-thiocyanatoriboflavin (4b) and 6-mercaptoriboflavin (5b). 6-Thiocyanatoriboflavin (4b) in $0.05 \mathrm{M}$ potassium phosphate buffer, pH 7.0 , containing $100 \mu \mathrm{M}$ EDTA $(-)$ was reacted with $0.4 \mathrm{mM}$ dithiothreitol to produce 6-mercaptoflavin (5b) $(--)$. Extinction coefficients were determined by titration with riboflavin-binding protein, as shown in Figure 8.

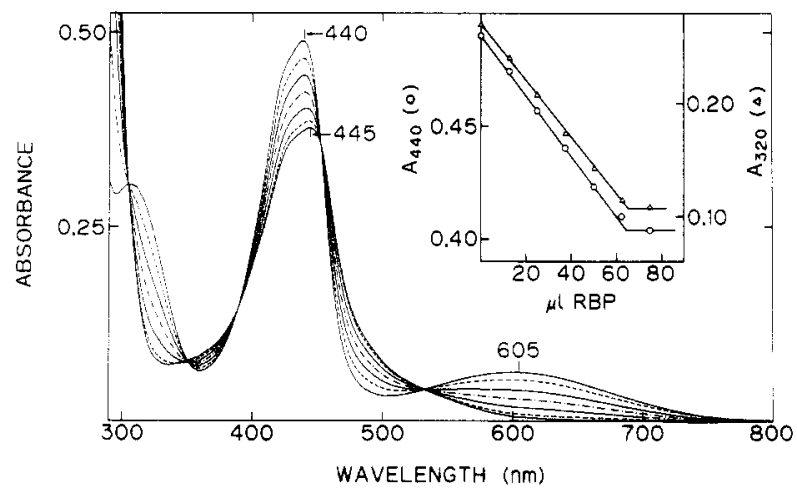

FIGURE 8: Titration of 6-mercaptoriboflavin (5b) with riboflavinbinding protein. 6-Mercaptoriboflavin (5b) (volume $=1 \mathrm{~mL}$ ) prepared as described in Figure 7 (curve with highest absorbance at $440 \mathrm{~nm}$ ) was titrated with $12.5-\mu \mathrm{L}$ aliquots of $3.81 \times 10^{-4} \mathrm{M}$ aporiboflavinbinding protein (successive curves). The absorbance values at 440 and $320 \mathrm{~nm}$, corrected for dilution, are shown in the inset. The end point of $65 \mu \mathrm{L}$ of riboflavin-binding protein permits the extinction coefficient of the starting 6-mercaptoriboflavin (5b) to be calculated: $\epsilon_{440}=19600 \mathrm{M}^{-1} \mathrm{~cm}^{-1}$.

flavins to 6-mercaptoflavins by reductive elimination of cyanide, carried out with $\mathrm{Na}_{2} \mathrm{~S}_{2} \mathrm{O}_{4}$ or photochemically (Ghisla et al., 1980). The ready dimerization of the 6-mercaptoflavin by oxidation (Ghisla et al., 1980), however, did not seem to make it an attractive candidate as an active site probe for flavoproteins. Such problems, however, are easily overcome by treatment of 6-thiocyanatoflavins with dithiothreitol, which brings about their rapid conversion to the corresponding 6mercaptoflavin (second-order rate constant: $\sim 1 \times 10^{3} \mathrm{M}^{-1}$ $\mathrm{min}^{-1}$ for 6-thiocyanatoriboflavin at $\mathrm{pH} 7.0,20^{\circ} \mathrm{C}$ ) and at the same time stabilizes the 6-mercaptoflavin against oxidative dimerization (cf. Figure 7). Thus, the conversion can be carried out with nearly stoichiometric concentrations of dithiothreitol, and provided that EDTA $(>10 \mu \mathrm{M})$ is present to prevent trace metal catalyzed oxidation of thiols, the resulting 6-mercaptoflavins are stable for hours, permitting their incorporation into apoproteins. Under the conditions employed, this conversion does not appear to result from reduction of the flavin and elimination of cyanide, as found earlier for the low-pH photochemical reaction (Ghisla et al., 1980). Details of the possible mechanism will be published later ( $\mathrm{V}$. Massey, S. Ghisla, and K. Yagi, unpublished results).

The extinction coefficients were determined by titration of the 6-mercaptoriboflavin with riboflavin-binding protein, as shown in Figure 8. Riboflavin-binding protein is known to bind to neutral flavins with great avidity but weakly, or not

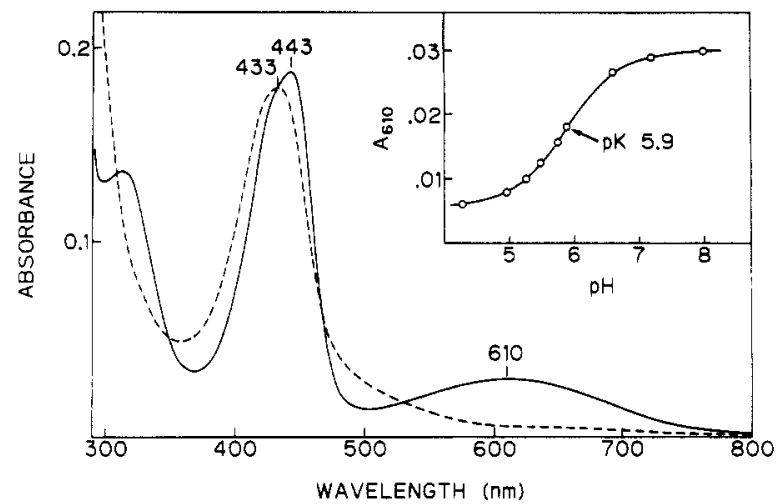

FIGURE 9: Spectra of 6-mercapto-FAD (5d) in its neutral (protonated) and anionic states. 6-Thiocyanato-FAD (4d) $(\sim 10 \mu \mathrm{M})$ in $0.02 \mathrm{M}$ pyrophosphate buffer, $\mathrm{pH} 8.0$, containing $1 \mathrm{mM}$ EDTA was converted to 6-mercaptoflavin by addition of $5 \mathrm{mM}$ dithiothreitol $(-)$. The $\mathrm{pH}$ was then lowered stepwise by the addition of small amounts of finely powdered citric acid and the spectrum recorded after each addition. Isosbestic points at $530,468,434$, and $350 \mathrm{~nm}$ were maintained to the lowest $\mathrm{pH}$ used, $\mathrm{pH} 4.3(--)$. The inset shows the absorbance at $610 \mathrm{~nm}$ as a function of $\mathrm{pH}$, yielding a $\mathrm{pK}$ of 5.9 .

at all, to negatively charged flavins (Blankenhorn et al., 1975; Becvar \& Palmer, 1982). The pronounced spectral shifts seen with riboflavin-binding protein are similar to those found with 6-hydroxy-and 8-hydroxyriboflavin (Massey, 1980) and with 8-mercaptoriboflavin (Massey et al., 1979) and are again consistent with preferential binding of the neutral flavin, even though the titration was carried out at a $\mathrm{pH}$ where the free flavin was in its anionic form (cf. Figure 9).

The $\mathrm{p} K$ of the thiol function of 6-mercapto-FAD was determined by recording the spectrum in the presence of excess dithiothreitol and by changing the $\mathrm{pH}$ by the addition of powdered citric acid. Figure 9 shows the spectra in the anionic and neutral forms, and the inset of $A_{610}$ vs. $\mathrm{pH}$ shows a $\mathrm{pK}$ of 5.9 , slightly lower than the value of 6.4 given by Steenkamp et al. (1978) for 6-mercapto-FMN. This is consistent with the previously determined $\mathrm{p} K$ values of hydroxy- and mercaptoflavins substituted at the 6- and 8-positions. The $\mathrm{p} K$ of 6-hydroxyriboflavin is 7.1 (Mayhew et al., 1974), while that of 8-hydroxyriboflavin is 4.8 (Ghisla \& Mayhew, 1976), a difference of $2.3 \mathrm{pH}$ units. 8-Mercaptoriboflavin has a $\mathrm{pK}$ of 3.8 (Massey et al., 1979), $2.1 \mathrm{pH}$ units below that of 6 mercapto-FAD. This property of 6-mercaptoflavins, and the pronounced spectral differences between the neutral and anionic forms, should make them useful probes of the protein environment of the bound flavin, as has proved possible with the other 6- and 8-substituted hydroxy- and mercaptoflavins. Furthermore, the chemical reactivity of the mercapto function toward peroxides and alkylating agents should serve to probe solvent accessibility to this portion of the flavin in various flavoproteins, as has proved possible with flavins carrying sulfur substituents at the 2-, 4- and 8-positions (Schopfer et al., 1981; Biemann et al., 1983; Massey et al., 1984).

\section{ACKNOWLEDGMENTS}

We thank Drs. N. Ohishi, S. Kobayashi, and T. Iida of the Institute of Applied Biochemistry for their help during the course of this work and Dr. W. Pfleiderer, University of Konstanz, for his comments and suggestions.

Registry No. 1a, 72184-57-7; 1b, 73652-55-8; 1d, 101760-86-5; 2a, 101760-81-0; 3a, 101760-82-1; 3b, 101760-83-2; 3c, 101760-92-3; 3d, 101760-85-4; 4b, 73647-56-0; 4d, 101760-87-6; 5b, 101760-88-7; 5c, 101760-89-8; 5d, 101760-90-1; 6, 101760-91-2; 8a, 101760-84-3; $\mathrm{Cu}, 7440-50-8$; old yellow enzyme, 9001-68-7; lactate oxidase, 
9028-72-2; D-amino acid oxidase, 9000-88-8.

\section{REFERENCES}

Abramovitch, R. A., \& Kyba, E. P. (1971) in The Chemistry of the Azido Group (Patai, S., Ed.) pp 221-329, Wiley, New York.

Abramovitz, A. S., \& Massey, V. (1976a) J. Biol. Chem. 251, 5321-5326.

Abramovitz, A. S., \& Massey, V. (1976b) J. Biol. Chem. 251, 5327-5336.

Bayley, H., \& Knowles, J. R. (1977) Annu. Rev. Biochem. 48, 289-325.

Becvar, J., \& Palmer, G. (1982) J. Biol. Chem. 257, 5607-5617.

Biemann, M., Claiborne, A., Ghisla, S., Massey, V., \& Hemmerich, P. (1983) J. Biol. Chem. 258, 5440-5448.

Blankenhorn, G., Osuga, D. T., Lee, H. S., \& Feeney, R. E. (1975) Biochim. Biophys. Acta 386, 470-478.

Choong, Y. S., \& Massey, V. (1981) J. Biol. Chem. 256, 8671-8678.

Choong, Y. S., Maxwell, G., Shepherd, N. G., \& Sullivan, P. A. (1975) Biochem. J. 145, 37-45.

Chowdhry, V., \& Westheimer, F. H. (1979) Annu. Rev. Biochem. 48, 293-325.

Fitzpatrick, P. F., Ghisla, S., \& Massey, V. (1985) J. Biol. Chem. 260, 8483-8491.

Ghisla, S., \& Mayhew, S. G. (1976) Eur. J. Biochem. 63, 373-390.

Ghisla, S., \& Mayhew, S. G. (1980) Methods Enzymol. 66, 241-253.

Ghisla, S., Massey, V., \& Mayhew, S. G. (1976) in Flavins and Flavoproteins (Singer, T. P., Ed.) pp 334-340, Elsevier, Amsterdam.

Ghisla, S., Kenney, W. C., Knappe, W. R., McIntire, W., \& Singer, T. P. (1980) Biochemistry 12, 2537-2544.

Ghisla, S., Fitzpatrick, P. F., \& Massey, V. (1984) in Flavins and Flavoproteins (Bray, R. C., Engel, P. C., \& Mayhew, S. G., Eds.) pp 751-754, de Gruyter, Berlin.

Harzer, G., \& Ghisla, S. (1979) in Chemistry and Biology of Pteridines (Kisliuk, R., \& Brown, G., Eds.) pp 37-42, Elsevier, New York.

Hastings, J. W., Ghisla, S., Kurfürst, M., \& Hemmerich, P. (1981) in Proceedings of the Second International Congress of Chemiluminescence and Bioluminescence (DeLuca, M., \& McElroy, W., Eds.) pp 97-101, Academic, New York.

Kasai, S., Sugimoto, K., Miura, R., Yamano, T., \& Matsui, K. (1983) J. Biochem. (Tokyo) 93, 397-403.

Knappe, W. R. (1979) Liebigs Ann. Chem., 1062-1080.

Krauth-Siegel, L., Ghisla, S., \& Schirmer, H. (1985) Eur. J. Biochem. 148, 335-344.

Lund, H. (1975) in Chemistry and Biology of Pteridines (Pfleiderer, W., Ed.) p 645, de Gruyter, Berlin.

Lwowski, W. (1980) Ann. N.Y. Acad. Sci. 346, 491-500.
Massey, V. (1980) in Photoreception and Sensory Transduction in Aneural Organisms (Lenci, F., \& Colombetti, G., Eds.) pp 253-269, Plenum, Oxford.

Massey, V., \& Curti, B. (1966) J. Biol. Chem. 241, 3417-3423.

Massey, V., Ghisla, S., \& Moore, A. (1979) J. Biol. Chem. 254, 9640-9650.

Massey, V., Claiborne, A., Biemann, M., \& Ghisla, S. (1984) J. Biol. Chem. 259, 9667-9678.

Mayhew, S. G., \& Massey, V. (1969) J. Biol. Chem. 244, 794-802.

Mayhew, S. G., Whitfield, C. D., Ghisla, S., \& SchumanJorns, M. (1974) Eur. J. Biochem. 44, 570-591.

Mengel, R., Pfleiderer, W., \& Knappe, W. R. (1977) Tetrahedron Lett. 32, 2817-2820.

Müller, F., Walker, W. H., \& Hemmerich, P. (1966) Helv. Chim. Acta 49, 2365-2369.

Pfleiderer, W. (1957) Chem. Ber. 90, 2604-2616.

Pfleiderer, W., \& Mengel R. (1971) Chem. Ber. 104, 2293-2312.

Pfleiderer, W., Bunting, J. W., Perrin, D. D., \& Nübel, G. (1966) Chem. Ber. 99, 3503-3523.

Pfleiderer, W., Mengel, R., \& Hemmerich, P. (1971) Chem. Ber. 104, 2273-2292.

Quay, S., \& Massey, V. (1977) Biochemistry 16, 3348-3354.

Ram, V. J., Knappe, W. R., \& Pfleiderer, W. (1982) Liebigs Ann. Chem., 762-774.

Reiser, A., \& Wagner, H. M. (1971) in The Chemistry of the Azido Group (Patai, S., Ed.) pp 441-501, Wiley, New York.

Schöllnhammer, G., \& Hemmerich, P. (1974) Eur. J. Biochem. 44, 561-577.

Schopfer, L. M., Massey, V., \& Claiborne, A. (1981) J. Biol. Chem. 265, 7329-7339.

Spencer, R., Fisher, J., \& Walsh, C. (1976) Biochemistry 15, 1043-1053.

Steenkamp, D. J., McIntire, W., \& Kenney, W. C. (1978) $J$. Biol. Chem. 253, 2818-2824.

Sullivan, P. A., Choong, Y. S., Schreurs, W. G., Cutfield, J. F., \& Shepherd, N. G. (1977) Biochem. J. 165, 375-383.

Thorpe, C., \& Massey, V. (1983) Biochemistry 22, 2972-2978.

Visser, A. J. W., \& Müller, F. (1979) Helv. Chim. Acta 62, 593-608.

Walsh, C., Fisher, J., Spencer, R., Graham, D. W., Ashton, W. T., Brown, J. E., Brown, R. D., \& Rogers, E. F. (1978) Biochemistry 17, 1942-1951.

Wassink, J. H., \& Mayhew, S. G. (1975) Anal. Biochem. 68, 609-616

Yagi, K., \& Ozawa, T. (1962) Biochim. Biophys. Acta 56, 413-419.

Yagi, K., Naoi, M., Harada, M., Okamura, K., Hidaka, H., Ozawa, T., \& Kotaki, A. (1967) J. Biochem. (Tokyo) 61, $580-597$. 